\title{
Experimental Investigation of Flat Fan Spray with Solid Impurities
}

\author{
Zhaobo Li ${ }^{1}$, Cheng $\mathrm{Li}^{2}$ \\ ${ }^{1}$ Chongqing Nankai Secondary School \\ 1st Sha'nan Str,Chongqing, China \\ Contact Author: \\ ${ }^{2}$ National Energy Technology Lab \\ 3610 Collins Ferry Rd, Morgantown, WV 26505, USA \\ cheng.li@netl.doe.gov
}

\begin{abstract}
Controlling the droplet size distribution generated in a spray is critical for a wide spectrum of industrial applications. The current paper investigates experimentally the spray droplets formation with addition of solid impurities with size ranging from $90 \mu \mathrm{m}$ $400 \mu \mathrm{m}$. The focus is on the effects of solid impurities on planar spray breakup dynamics and resulting droplet size distribution. The experiment was conducted using a standard flat fan Teejet XR 110015 nozzle. The resulting spray lamella sheet and droplets formation are visualized using a digital single-lens reflex camera (DLSR) camera. Results show no hole formation for all tested cases as observed in previous studies with oil droplets or bubbles. Adding increasingly large particles to the spray solution causes the undisturbed lamella sheet area to decrease, especially noticeable for the $400 \mu \mathrm{m}$ case. The spray centerline breakup length decreases significantly with addition of solid particles especially with $400 \mu \mathrm{m}$ particles, which may cause the mean droplet size to increase. Such argument is proved to be true based on observation as well as quantitative particle sizing at lower pressure.
\end{abstract}

Keywords: Spray, imaging, solid impurities, breakup, droplet size distribution

\section{Introduction}

Modulation of the droplet size distribution in spray is critical for a broad range of industrial applications [1]. Particularly, for example, during agricultural irrigation and pesticide applications, sprays are frequently generated through a hydraulic nozzle. Fine spray droplets can lead to off-target contamination with agrochemicals when they are drifted by the air, whereas larger droplets can result in a reduced coverage and deposition efficiency[2]. As a result, impurities such as fine oil droplets are frequently added to control the droplet size distribution of the spray [3]. A detailed understanding of the impurities on the spray dynamics and resulting droplet size distribution is critical in improving spray efficacy and eliminate agrochemical hazards

Droplet formation in water sprays is understood to be dominated by two processes, namely, ligament formation brought about by Squire wave development and subsequent ligament breakup due to capillary instabilities[4]. Conversely, the introduction of solid or liquid impurities leads to perforations (hole formation) on the liquid sheet prior to ligament formation, which increases the characteristic thickness of the liquid sheet upon breakup into ligaments, presumably generating coarser spray droplets. Dombrowski and Fraser[5] provided extensive qualitative description of liquid sheets produced by flat fan nozzles using various type of impurities. The authors found only unwettable impurities caused the hole formation and speculated that the size of the particles must be comparable to the sheet thickness to cause holes to form. Recent studies mostly focus on the effects oil droplet as impurities on the spray characteristics. Notably, using high-speed imaging with a dyed spray, Vernay et al. [6,7] measured the thickness and expansion rate of holes in a model experiment involving liquid sheets with oil droplets of volume median diameter of $\sim 20 \mu \mathrm{m}$. In line with the proposed mechanism from Hilz et al.[8], they illustrated a pre-hole process whose growth dynamics matches that of liquid spreading on another liquid with higher surface tension. However, such a mechanism fails to explain the perforations in sprays with solid impurities

This paper focuses on the effects of solid impurities on planar spray breakup dynamics and resulting droplet size distribution. Experiments are conducted using a standard Teejet flat fan nozzle operated at a constant flow rate and various pressures. Wheat flour, sand, and wood particles with varying particle sizes are used as solid impurities. The data include high-speed visualizations of processes affecting the Squire wave development, hole formation, and ligament breakup. The 
focused spray droplet image is identified to quantify the droplet size distribution. Moreover, the time-resolved image sequence is used to track droplets to calculate the velocity spectrum of the droplets.

\section{Materials and Methods}

\subsection{Experiment setup}

The flat-fan spray seed without or with solid particles with varying sizes are generated according to the experiment setup as shown in Fig. 1. The solid particle/water mixture is prepared immediately before the experiments to prevent from particles settling or agglomerations. The suspension is then filled in a pressure vessel to provide spray liquid to the nozzle to form flat fan spray. The system has been designed with adjustable valve to control the supply pressure to work under various flow rate conditions. An air pump is connected to the pressure vessel to sustain constant pressure while spraying. The nozzle is installed to spray downward to minimize effects of gravity bias on droplet size distribution as well preserving the symmetry of the shape of the spray. The camera used in the experiment is a Canon EOS 5D DLSR camera with Canon EF 24-70mm f/2.8L USM Standard Zoom Lens. Focal length is fixed at $70 \mathrm{~mm}$ while the exposure time is set at 1/8000 s, with $f$ number 5.6 and iso 200. Back lighting by Philips LED Luminaire at power $16 \times 2 \mathrm{~W}$ are used to illuminate the spraying process.

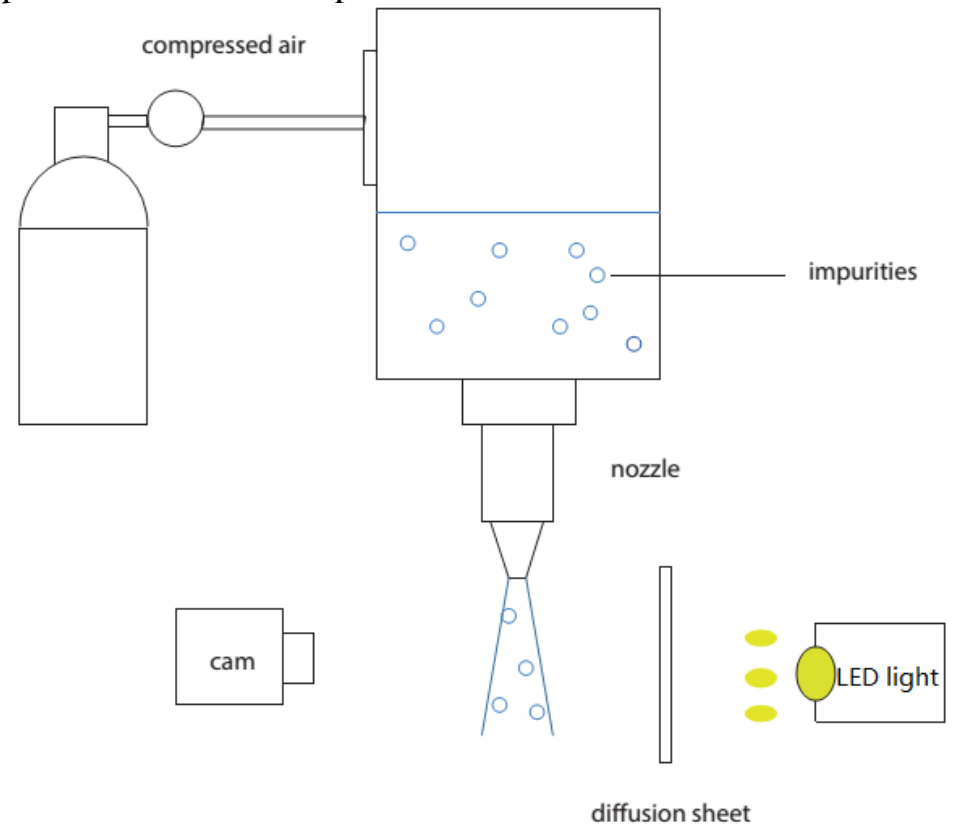

Fig. 1: Experimental setup for the formation and observation of the flat-fan spray.

\subsection{Material and test conditions}

Table 1 provides the material used in forming the spray. Distilled water are used in water only case as well impurity suspension cases. The whole setup is placed at a temperature of $25^{\circ} \mathrm{C}$ and an atmosphere pressure of $99.3 \mathrm{kpa}$. Three different particles with diameters 90,180 , and $400 \mu \mathrm{m}$ are used as impurities. The impurities are added to the water at a constant concentration of $50 \mathrm{~g} / \mathrm{L}$. For all water or particle suspensions, varying working pressure are also tested at 34.5, 68.9, and $137.9 \mathrm{kPa}$. The flow rate was measured for different working pressures using distilled water. Fig. 2 shows the flow rate $v s$ $(p)^{1 / 2}$; indeed, all data points fit well to straight line confirming a match of Bernoulli equation. Namely, assuming viscous loss and spray velocity before spraying is negligible, the Bernoulli equation gives:

$$
p_{\text {after }}+\frac{1}{2} \rho v^{2}=p_{\text {before }}
$$

where $\mathrm{v}$ is the velocity at nozzle opening, $p_{\text {after }}$ and $p_{\text {before }}$ are the pressure after and before spray respectively. One finds that the flow rate $(q)$ follows:

$$
q=v A=A \sqrt{2\left(p_{\text {after }}-p_{\text {before }}\right) / \rho}
$$


where $A$ is the area of nozzle opening. The relationship clearly demonstrate a $q \sim p^{1 / 2}$ dependence.

Table 1. Material properties used in the experiments.

\begin{tabular}{|c|c|c|}
\hline & Mean diameter $/ \boldsymbol{\mu m}$ & Density $\mathbf{( g / m L )}$ \\
\hline Distilled water & N/A & 1.00 \\
\hline Flour particle type 1 & 90 & 0.52 \\
\hline Flour particle type 2 & 180 & 0.48 \\
\hline Sand particle & 400 & 2.50 \\
\hline
\end{tabular}

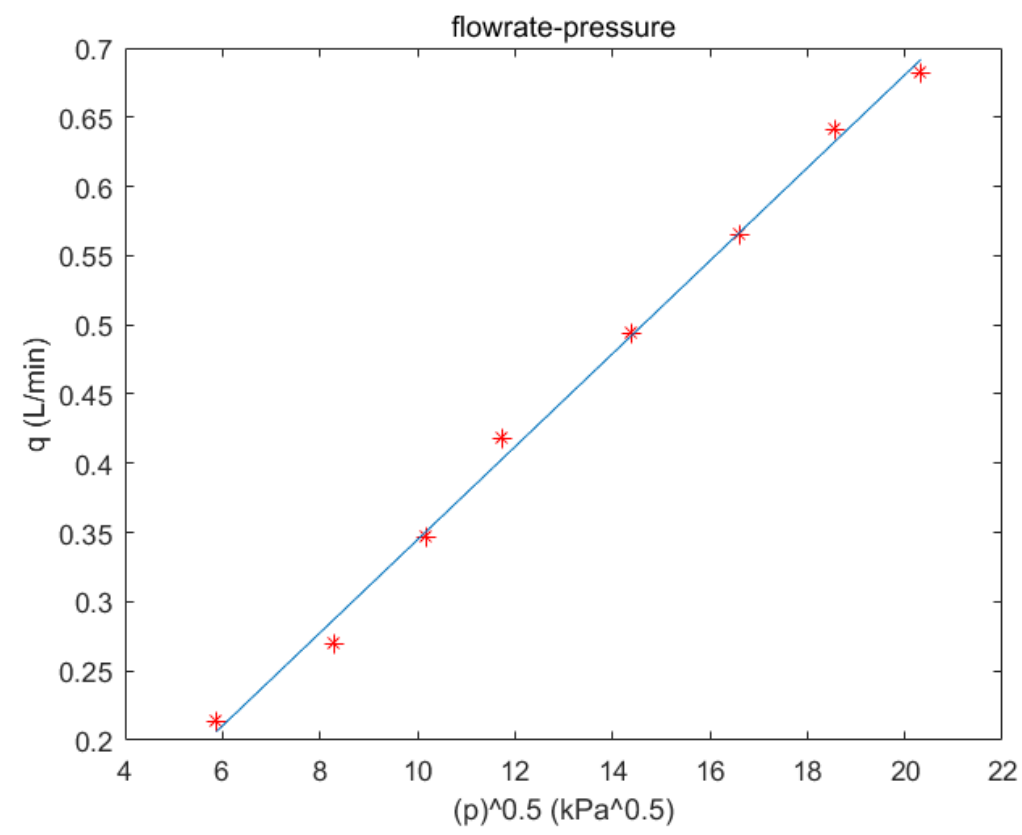

Fig. 2: The flow rate $v s$ pressure. Red star symbol corresponds to experimental data and blue straight line is a linear fit with correlation coefficient 0.9981 .

\section{Results}

\subsection{General Breakup Characteristics With and Without Impurities}

In a first set of experiments, we fix the supply pressure to $34.5 \mathrm{kPa}$ and vary the types of the particle suspension. For all particle cases, the concentrations are also fixed to $50 \mathrm{~g} / \mathrm{L}$. Representative images of the spray showing lamella sheet formation along with subsequent breakup are provided in Fig. 3. As it shows, the general flat-fan shape of the lamella sheet is similar for all cases. The angle of the spray is significantly less than the nominal angle of 100 degrees, since it's operating at a lower pressure than the standard working pressure. The size of the generated particle seems to be larger for $180 \mu \mathrm{m}, 400 \mu \mathrm{m}$ suspensions (Fig. 3c, d) than for water only and $90 \mu \mathrm{m}$ cases (Fig. 3a, b).

The spray is inherently unsteady. To account for the temporal intermittency of the sprays, we used several images from the same test case to form an overlaid image to demonstrate the temporally averaged spray shape as shown in Fig. 4 . The temporally averaged spray shows a larger spray angle compared to instantaneous spray images. The angle remains at around $31^{\circ}$ for water only, $90 \mu \mathrm{m}$, and $180 \mu \mathrm{m}$ case, but decreases slightly to $23^{\circ}$ at $400 \mu \mathrm{m}$. Moreover, adding increasingly large particles to the spray solution causes the undisturbed lamella sheet area to decrease, especially for the $400 \mu \mathrm{m}$ case (Fig. $4 \mathrm{~d}$ ) This is presumably due to the larger particles in the lamella sheet is prone to produce larger disturbance than those small to no particle cases. Finally, the spray centreline breakup length decreases significantly with addition of solid particles, from 
water only case $(16.7 \mathrm{~mm})$ to $400 \mu \mathrm{m}$ particle case $(12.9 \mathrm{~mm})$. This is consistent with previous studies with addition of oil droplets or bubbles [9]. This is also consistent with the observation that the droplet is larger for larger particles suspension sprays. Since the thickness of sheet is larger at an earlier breakup, the characteristic length of the formed droplets tend to be larger than those with a later breakup. These qualitative observations are investigated further through quantitative measurement of the droplet size distribution shown in the next section.

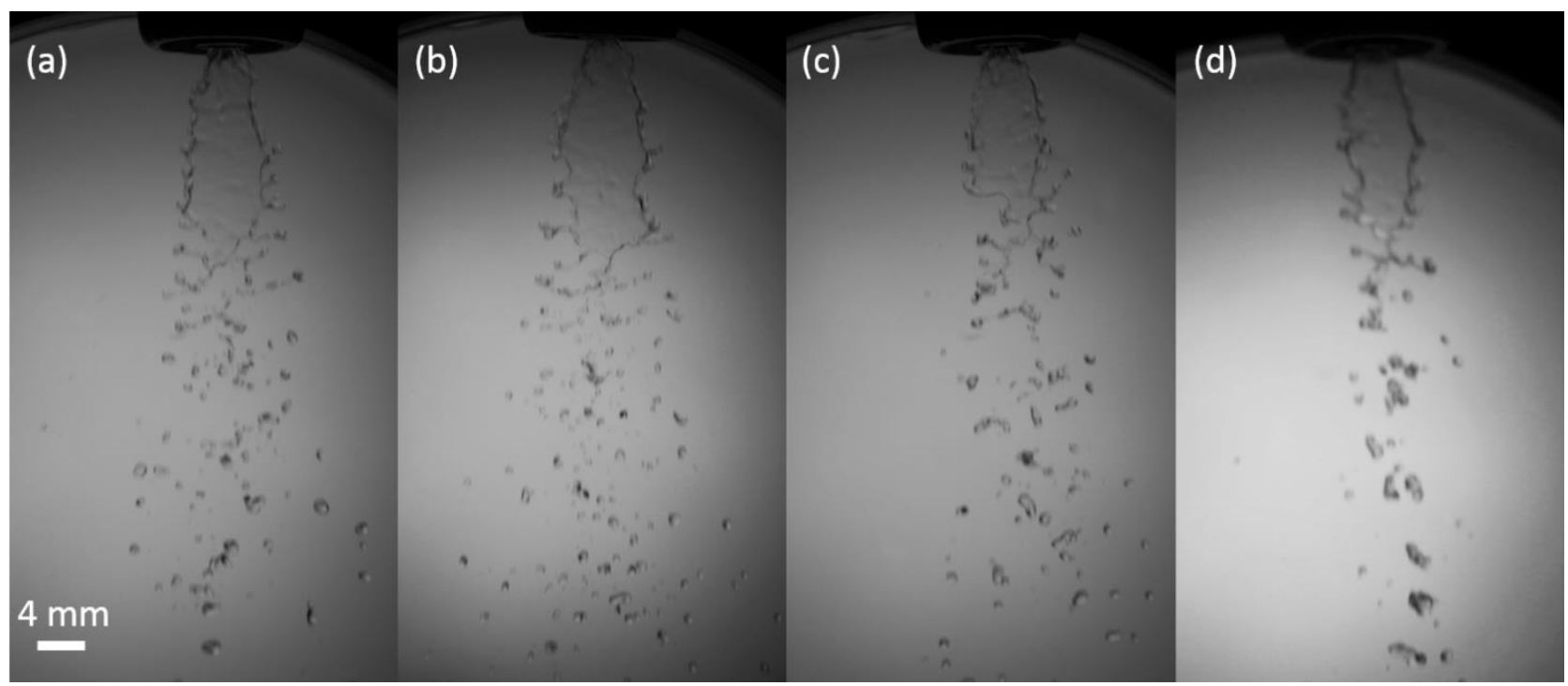

Fig. 3. Samples of spray images showing lamella sheet formation and spray breakup into small droplets with and without particles at $34.5 \mathrm{kPa}$. (a) water only, (b) $90 \mu \mathrm{m}$ flour particle, (c) $180 \mu \mathrm{m}$ flour particle; (d) $400 \mu \mathrm{m}$ sand particle.

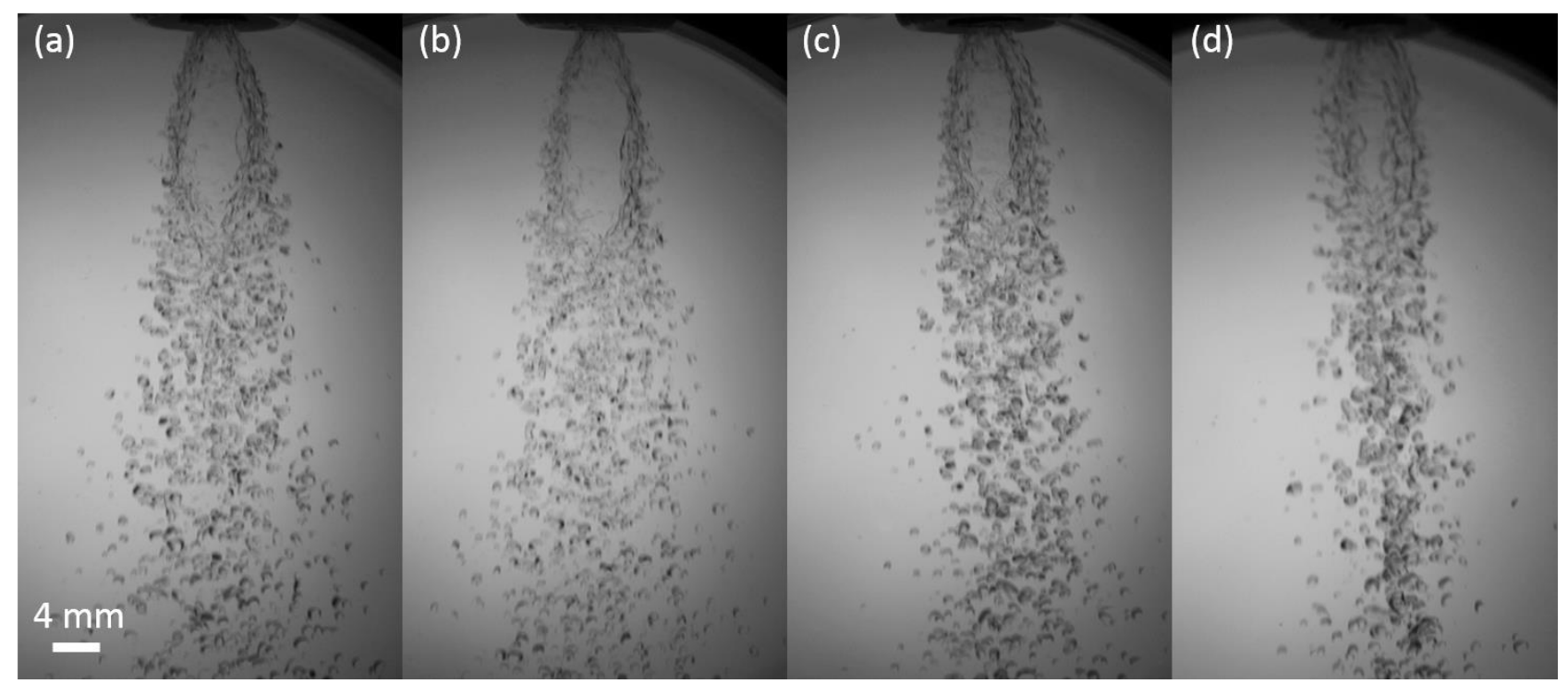

Fig. 4. Overlaid of eight spray images showing time averaged behavior of the spray with and without particles at $34.5 \mathrm{kPa}$. (a) water only, (b) $90 \mu \mathrm{m}$ flour particle, (c) $180 \mu \mathrm{m}$ flour particle; (d) $400 \mu \mathrm{m}$ sand particle. 

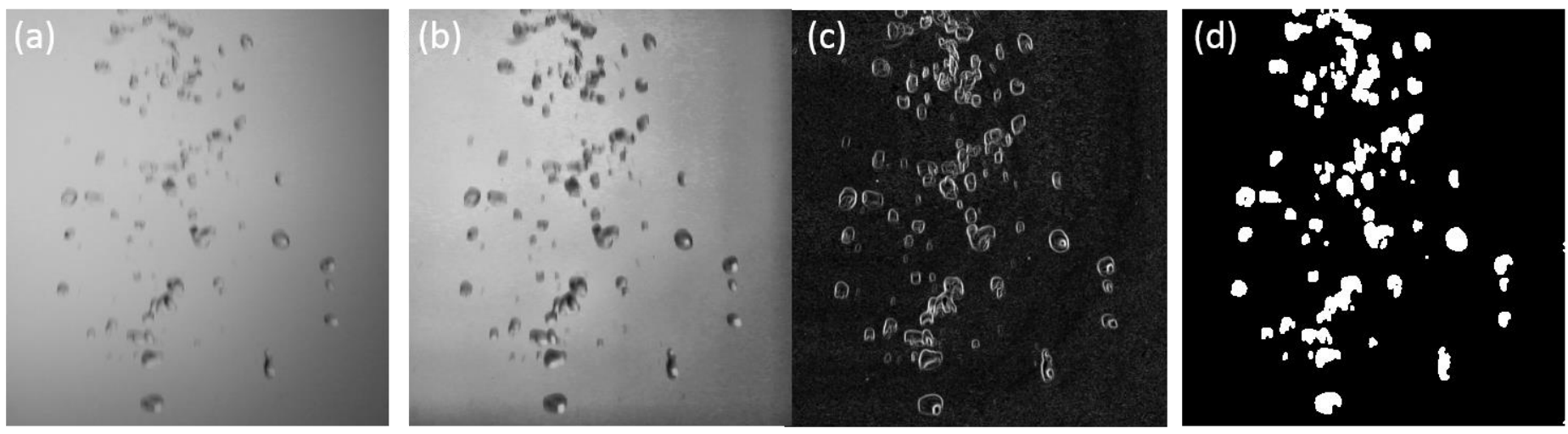

Fig. 5. Image processing to identify droplet size. (a) raw image, (b) enhanced image using adaptive histogram equalization and wiener filtering, (c) gradient magnitude calculation, and (d) binarized droplet image.

(a)

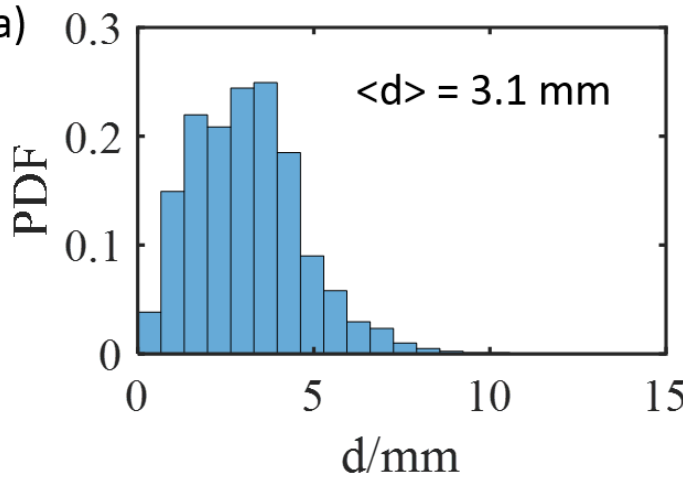

(c)

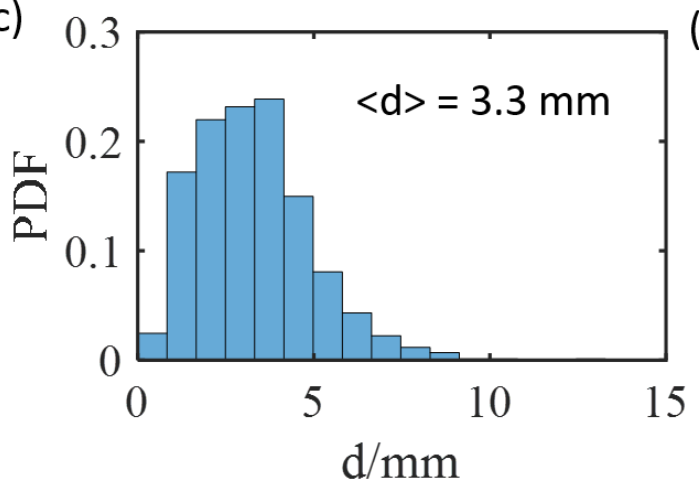

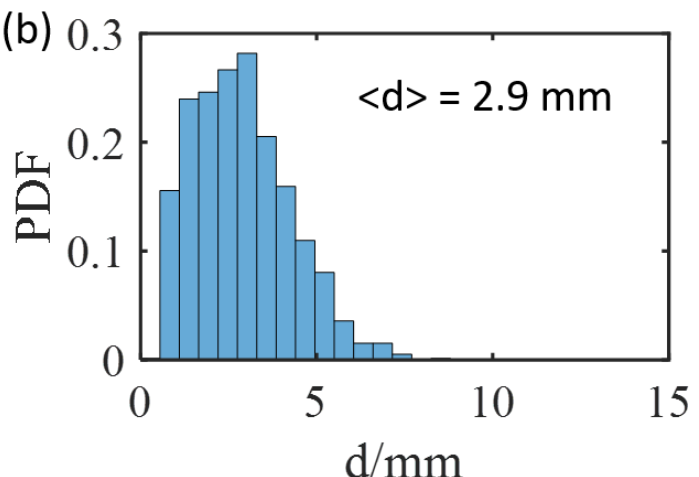

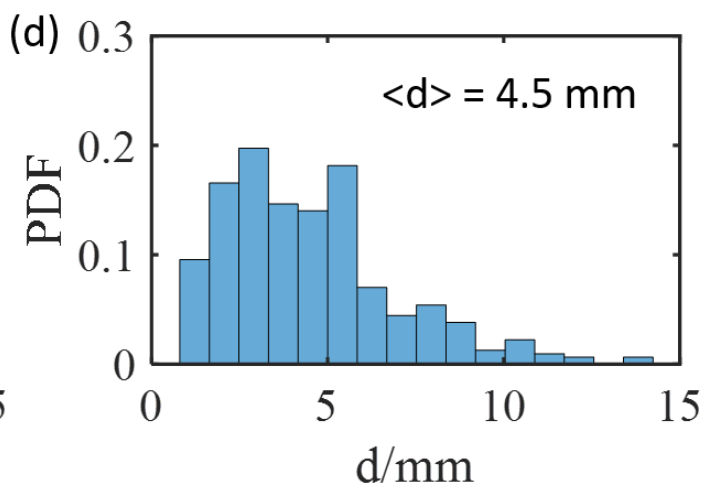

Fig. 6 Droplet size distribution for water only and particles suspensions with varying sizes.

\subsection{Droplet Size Distribution}

To quantify the effects of solid impurities on the generated spray particle size distribution, the images are processed to extract individual droplet size after breakup. The processing is conducted using Matlab Image Processing toolbox. The associated procedures are demonstrated in Fig. 5. First the raw image (Fig5a) is enhanced using adaptive histogram equalization and a wiener fileter with a 3 by 3 pixels window (Fig 5b). The enhanced images are then used to calculate the image gradient magnitude map which is used to identify the boundaries of droplets. Fig.5d shows the resultant threshold droplet image for particle size calculation. Fig. 6 shows the droplet size distribution for four cases with and without particles. As is shown, the general shape of the distribution is similar for four case, all non-Gaussian and with a positive skewness. For 
the first three case, the PDF results in almost the same mean droplet size $(<\mathrm{d}>)$. The effects of adding solid particles becomes noticeable only when the solid particle size reaches $400 \mu \mathrm{m}$. The $<\mathrm{d}>$ increases to $4.5 \mathrm{~mm}$ for $400 \mu \mathrm{m}$ case. That is a $45 \%$ increase in size and a $206 \%$ increase in volume.

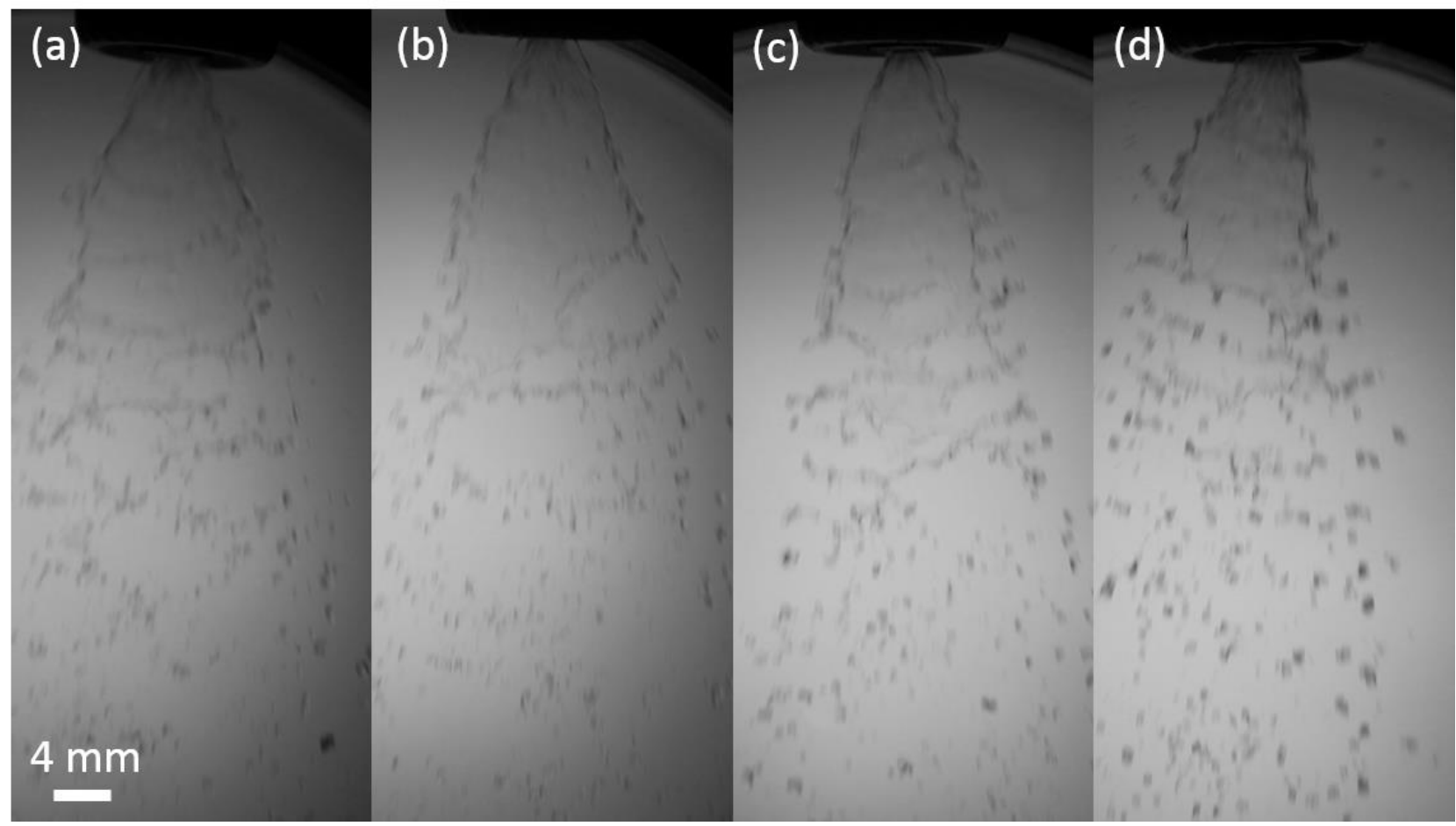

Fig. 7. Samples of spray images showing lamella sheet formation and spray breakup into small droplets with and without particles at $68.9 \mathrm{kPa}$. (a) water only, (b) $90 \mu \mathrm{m}$ flour particle, (c) $180 \mu \mathrm{m}$ flour particle; (d) $400 \mu \mathrm{m}$ sand particle.

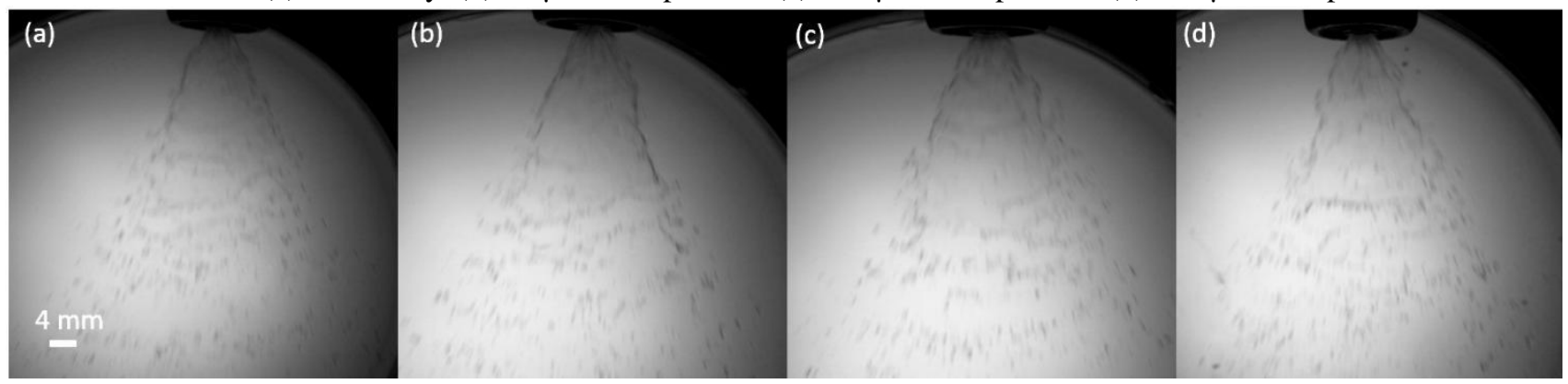

Fig. 8. Samples of spray images showing lamella sheet formation and spray breakup into small droplets with and without particles at $137.9 \mathrm{kPa}$. (a) water only, (b) $90 \mu \mathrm{m}$ flour particle, (c) $180 \mu \mathrm{m}$ flour particle; (d) $400 \mu \mathrm{m}$ sand particle.

\subsection{Effects of pressure}

Fig. 7 and Fig. 8 provides the sample images for cases at spraying pressure of $68.9 \mathrm{kPa}$ and $137.9 \mathrm{kPa}$ respectively. For $68.9 \mathrm{kPa}$ case, the earlier breakup is observed for the $400 \mu \mathrm{m}$ sand particle case, whereas the breakup length remains almost unchanged for $90 \mu \mathrm{m}$ flour particle case, and slightly increase for $180 \mu \mathrm{m}$ case. We don't have an explanation for such a increase in lamella sheet length, which is in need for further investigation. Also, based on the images, the characteristic droplet size seems to increase with addition of $400 \mu \mathrm{m}$ particles. However, current imaging system is unable to capture those quick moving droplets for droplet size analysis conducted at section 2.2. For $137.9 \mathrm{kPa}$ spray (Fig. 8), much finer droplets are generated. Such a decrease in characteristic droplet size is a result of pressure increase as well as the associated spray angle increase. As the spray angle continue to increase, the lamella sheet thickness is reduced at the same distance away from 
the nozzle opening. Similar to $68.9 \mathrm{kPa}$, the breakup length is reduced for $400 \mu \mathrm{m}$ sand particle case, and larger droplets are generated compared to other cases.

\section{Conclusion}

Current study investigates the effects of solid impurities along with pressure variations on planar spray breakup dynamics as well as resulting droplet size distributions. A standard flat fan Teejet XR 110015 nozzle is used for generating the spray. Particles with size ranging from $90-400 \mu \mathrm{m}$ is applied to generate water/particle mixture for spraying. Results show adding increasingly large particles to the spray solution causes the undisturbed lamella sheet area to decrease, especially noticeable for the $400 \mu \mathrm{m}$ case. The spray centerline breakup length decreases significantly with addition of solid particles especially with $400 \mu \mathrm{m}$ particles, which may cause the mean droplet size to increase. Such argument is proved to be true based on observation as well as quantitative particle sizing at lower pressure. No hole formation is observed for all tested cases as observed in many previous studies with oil droplets or bubbles[2,5,6,8-11]. Future studies are needed for furthering the understanding the mechanism of spray breakup using particle/water mixture. Fully resolved particle size measurement is needed for quantify particle size distribution for all test cases.

\section{References}

[1] A. Lefebvre, V. Mcdonell, Atomization and Sprays, Second Edition., 2017. doi:10.1016/0009-2509(90)87140-N.

[2] L.N. Opfer, Controlling Liquid Atomization using Dilute Emulsions: Mitigation of Pesticide Spray Drift, 17 (2014). http://tuprints.ulb.tu-darmstadt.de/4080/.

[3] C. Brown, A. Alix, D. Auteri, J. Gril, R. Hiederer, A. Huber, F. De Jong, M. Liess, S. Loutseti, N. Mackay, S. Maund, C. Pais, W. Reinert, M. Russell, T. Schad, R. Stadler, M. Styczen, LANDSCAPE AND MITIGATION FACTORS IN AQUATIC ECOLOGICAL RISK ASSESSMENT . Volume 2 . Detailed Technical Reviews Final Report of the FOCUS Working Group on Landscape and Mitigation Factors in Ecological Risk Assessment Acknowledgements Working Group Members, 2 (2007) 1-169.

[4] S. Kooij, R. Sijs, M.M. Denn, E. Villermaux, D. Bonn, What Determines the Drop Size in Sprays?, Phys. Rev. X. 8 (2018) 31019. doi:10.1103/PhysRevX.8.031019.

[5] N. Dombrowski, R.P. Fraser, A photographic investigation into the disintegration of liquid sheets, 247 (1954) 101130. doi:doi.org/10.1098/rsta.1954.0014.

[6] C. Vernay, L. Ramos, C. Ligoure, Bursting of Dilute Emulsion-Based Liquid Sheets Driven by a Marangoni Effect, Phys. Rev. Lett. 115 (2015) 198302. doi:10.1103/PhysRevLett.115.198302.

[7] C. Vernay, L. Ramos, J. Douzals, R. Goyal, J. Castaing, C. Ligoure, DROP IMPACT EXPERIMENT AS A MODEL EXPERIMENT TO INVESTIGATE THE ROLE OF OIL-IN-WATER EMULSIONS IN CONTROLLING THE DROP SIZE DISTRIBUTION OF AN AGRICULTURAL SPRAY, At. Sprays. (2016). doi:10.1615/AtomizSpr.2015013630.

[8] E. Hilz, A.W.P. Vermeer, M.A. Cohen Stuart, F.A.M. Leermakers, Mechanism of Perforation Based on Spreading Properties of Emulsified Oils, At. Sprays. 22 (2013) 1053-1075. doi:2854272.

[9] S.A. Cryer, A.L. Altieri, Role of large inhomogeneities in initiating liquid sheet breakup in agricultural atomisation, Biosyst. Eng. 163 (2017) 103-115. doi:10.1016/j.biosystemseng.2017.08.020.

[10] M.C. Butler Ellis, C.R. Tuck, How adjuvants influence spray formation with different hydraulic nozzles, Crop Prot. 18 (1999) 101-109. doi:10.1016/S0261-2194(98)00097-0.

[11] K. Qin, H. Tank, S.A. Wilson, B. Downer, L. Liu, CONTROLLING DROPLET-SIZE DISTRIBUTION USING OIL EMULSIONS IN AGRICULTURAL SPRAYS, At. Sprays. 20 (2010) 227-239. doi:10.1615/AtomizSpr.v20.i3.40. 